\title{
Modelling of the adhesive layer in mixed ceramic/metal armours subjected to impact
}

\author{
R. Zaera, S. Sánchez-Sáez, J.L. Pérez-Castellanos, C. Navarro* \\ Mechanical Engineering Department, Carlos III University of Madrid, Avda. de la Universidad 30, 28911 Leganés, Madrid, Spain
}

\begin{abstract}
The effect of the adhesive layer, used to bond ceramic tiles to a metallic plate, on the ballistic behaviour of ceramic/metal mixed armours is analysed mathematically and experimentally. Two types of adhesives, polyurethane (soft adhesive) and rubber modified epoxy resin (rigid adhesive), and different thicknesses, are considered in the study. Numerical simulations were made of low calibre projectiles impacting on alumina tiles backed by an aluminium plate, using a commercial finite difference code. Full scale tests were carried out to check the influence of the adhesive. An engineering model was also developed to provide a preliminary design tool taking account of the influence of the adhesive.
\end{abstract}

Keywords: Lightweight armours; B. Adhesion; B. Impact behaviour

\section{Introduction}

The main requirements of materials involved in armour design are: low density to reduce the total weight of the protected system; high bulk and shear moduli to prevent large deformations; high yielding stress to preserve the armour resistance to failure; and high dynamic tensile stress to avoid material rupture when tensile waves appear [1]. Metals, in general, fulfil all the requirements except that of density. Ceramics satisfy the first three demands but are brittle, which makes for extensive fragmentation due to the tensile waves generated by the compressive waves reflected from the free surfaces. Thus, no one material meets all the requirements. Mixed armours, however, made of ceramic tiles and a metallic plate, seem to form a very efficient shield against low and medium calibre projectiles since they combine the light weight and high resistance of ceramic with the ductility of metallic materials. A ceramic tile bonded to a metallic plate receives the impact (Fig. 1) and provides a saving of armour weight as compared to a steel armour of the same ballistic efficiency. As an example [2] of this last assertion, to defeat a $7.62 \mathrm{~mm}$ steel core projectile, travelling at $800 \mathrm{~m} / \mathrm{s}$, a steel plate of $95 \mathrm{~kg} / \mathrm{m}^{2}$ of areal density is necessary, whereas with an alumina/aluminium

\footnotetext{
* Corresponding author. Tel.: + 34-91-624-9491; fax: + 34-91-6249430 .

E-mail address: navarro@ing.uc3m.es (C. Navarro).
}

mixed armour, the areal density would be about $60 \mathrm{~kg} / \mathrm{m}^{2}$, thus giving a weight saving of $37 \%$ over the steel armour of the same ballistic efficiency. The presence of the ceramic tile is important to ensure the ballistic efficiency of the armour, but the ceramic material needs a backing plate to confine the ceramic fragments and to absorb the kinetic energy of the projectile during target penetration. So, for instance [3], an $11.4 \mathrm{~mm}$ thick AD85 tile (of $40 \mathrm{~kg} / \mathrm{m}^{2}$ areal density) defeats a 12.70 steel core projectile travelling at $95 \mathrm{~m} / \mathrm{s}$, whereas an armour of $6.35 \mathrm{~mm}$ thick AD85 tiles backed by a $6.35 \mathrm{~mm}$ thick aluminium plate, of the same total areal density as the previous one, defeats the same projectile, but now travelling at $250 \mathrm{~m} / \mathrm{s}$.

New AP projectiles have recently been developed which will make the old protective systems, such as those traditionally used for infantry fighting vehicles, aeroplanes and helicopters, ineffective against the new projectiles. This means that design solutions, based on the addition of new protections, must be adopted, and one of the most efficient modified protective systems consists in bonding ceramic tiles to the existing main armour [4], greatly improving its ballistic performance without adding significant weight. The ceramic facing can also be a single layer covering the whole back plate. In this case, the ballistic efficiency is higher due to the greater lateral confinement of the impact area. The main drawback is that the damage caused may extend over the whole surface, whereas with small tiles, this damage affects only the adjacent tiles. 


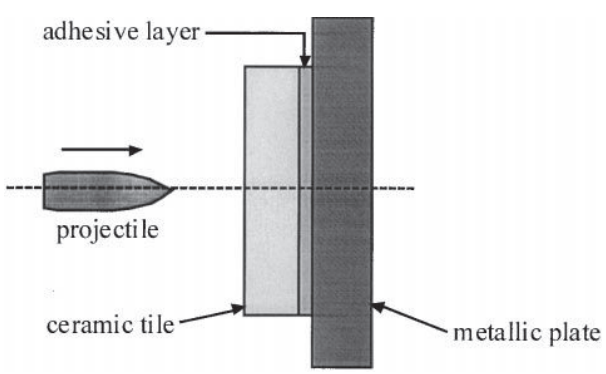

Fig. 1. Ceramic/metal panel.

But a problem arises in the ballistic behaviour of mixed armours: the influence of the layer of adhesive used to bond the ceramic tiles to the metallic backing plate has to be taken into account. Full-scale fire tests [5] have shown that the armour behaviour may be influenced significantly by the type of adhesive used, but no published research works inquire into the reasons of this influence. This study investigates the effect of the type of adhesive as well as of its
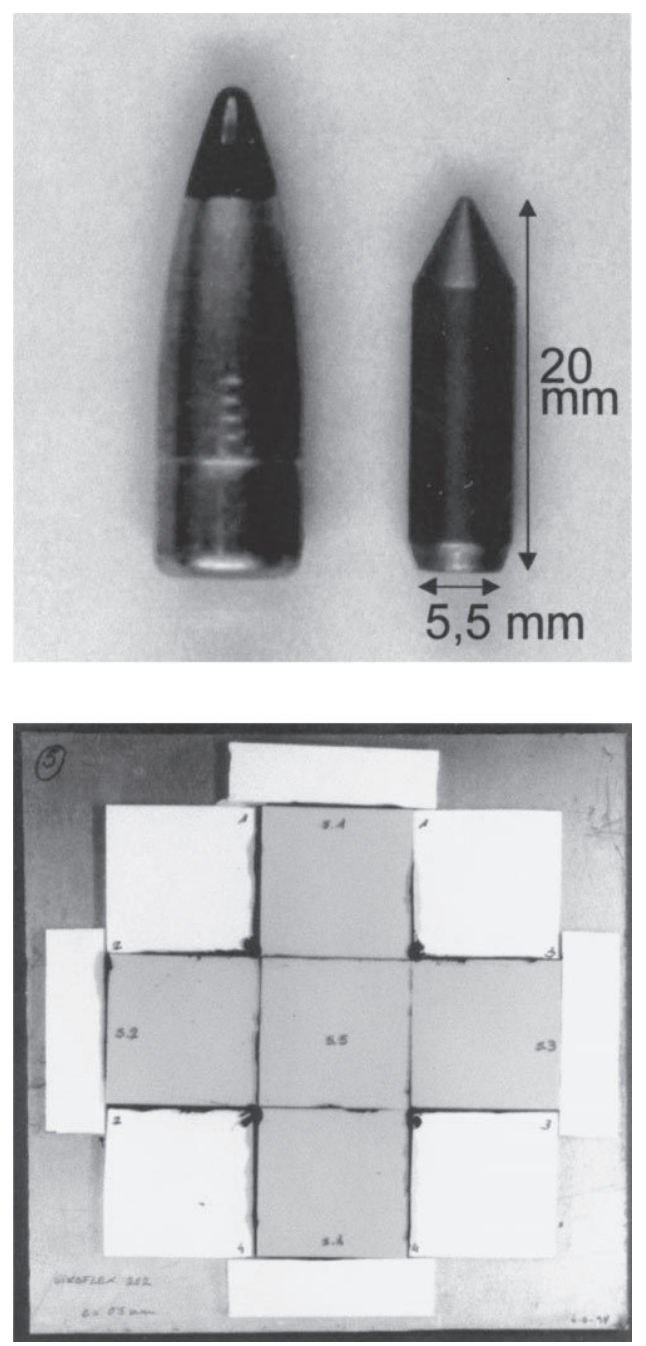

Fig. 2. 7.62 AP complete projectile and its tungsten carbide core (top). Ceramic/adhesive/metal panel (bottom).
Table 1

Mean values, for the polyurethane adhesive, of the elastic modulus at different strain rates

\begin{tabular}{ll}
\hline Strain rate $\left(\mathrm{s}^{-1}\right)$ & Elastic modulus $(\mathrm{MPa})$ \\
\hline 4200 & 108 \\
6200 & 230 \\
7000 & 280 \\
9100 & 490 \\
\hline
\end{tabular}

thickness. Several full-scale fire tests were carried out, firing low calibre projectiles against $6 \mathrm{~mm}$ thick alumina tiles bonded to $6 \mathrm{~mm}$ thick aluminium plates, to obtain a qualitative description of the phenomenon. Then a numerical simulation of the tests was performed, using a finite difference commercial computer code. Finally, a simplified engineering model was developed which incorporates the main features of the problem. All the analyses gave new data regarding the influence of the adhesive on the behaviour of mixed armour plating.

\section{Projectile, adhesives and target description}

The low calibre projectile used in this study was a LAPUA 7.62 armour-piercing (AP) projectile with a tungsten carbide core of $5.9 \mathrm{~g}$ and an impact velocity of $940 \mathrm{~m} / \mathrm{s}$ (Fig. 2). The armour is of $95 \%$ purity alumina tiles $(50 \mathrm{~mm} \times 50 \mathrm{~mm} \times 6 \mathrm{~mm})$ manufactured by Morgan Matroc, bonded to a 2017-T6 aluminium alloy plate (200 $\mathrm{mm} \times 200 \mathrm{~mm} \times 6 \mathrm{~mm})$. Two types of adhesives were used: polyurethane and rubber-toughened epoxy resin. For each type of adhesive, three thicknesses were considered: $0.5,1.0$ and $1.5 \mathrm{~mm}$. Fig. 2 also shows the laminated armour.

The mechanical behaviour of the two adhesives was determined at different strain rates using a compression split Hopkinson pressure bar. The results of the tests showed a dependence of the polyurethane elastic modulus on the strain rate. The absence of plastic behaviour indicated that a viscoelastic constitutive relationship may be adopted for this material. Table 1 gives the values of the elastic modulus obtained for the polyurethane. In contrast, the epoxy resin showed no dependence of the elastic modulus on strain rate, but this rate did have a significant influence on its plastic behaviour. Similar results were obtained by Grouch et al. [6]

Table 2

Mean values, for the epoxy resin, of the yield stress and of the slope of the stress-strain curve in the plastic range at different strain rates

\begin{tabular}{lll}
\hline Strain rate $\left(\mathrm{s}^{-1}\right)$ & Yield stress $(\mathrm{MPa})$ & Plastic range slope $(\mathrm{MPa})$ \\
\hline 2600 & 59 & 14 \\
3500 & 75 & 32 \\
4000 & 72 & 40 \\
\hline
\end{tabular}



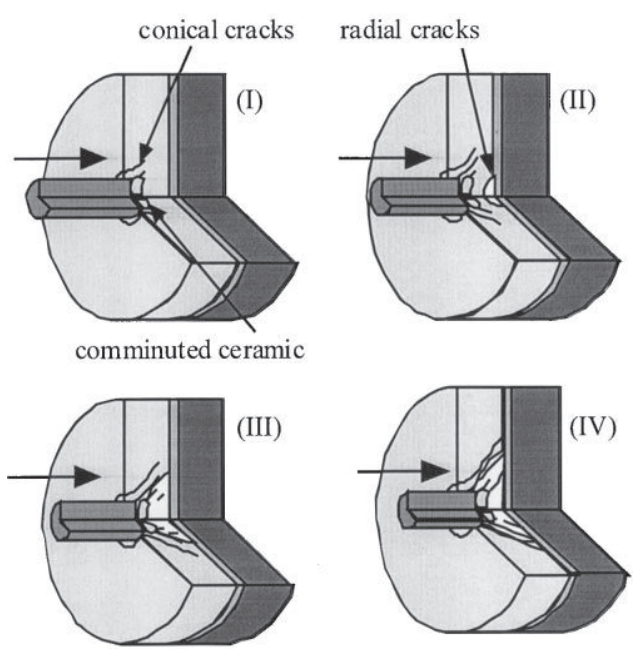

Fig. 3. Fragmentation of the ceramic tile during the first few microseconds of impact.

with a rubber-toughened epoxy resin. Table 2 gives the experimental results for the epoxy resin.

\section{Fragmentation process of the ceramic tile}

On impact, the ceramic material suffers damage over a wide area on account of its brittleness whereas the damage to the metallic plates is concentrated around the impact axis. The impacted ceramic tile is completely fragmented a few microseconds after impact, and cracks also appear in the adjacent tiles. This fragmentation process has been described in several studies [1,2,7]. A fractured ceramic conoid develops at the impact surface limiting the amount of ceramic that participates in transmitting the impact load to the metallic plate. A small volume of comminuted ceramic also forms in the vicinity of the projectile-ceramic interface, where high pressures appear. After impact, cracks are initiated on the rear face of the ceramic tile, travelling back to the projectile. These cracks are caused by the reflection, as tensile waves, of the compressive waves at the ceramic-adhesive interface. The consequence is a general break-up of the ceramic from the coalescence of the cracks (Fig. 3). The projectile can advance only if the pulverized ceramic material in its path is pushed ahead or to the sides. But this flow is impeded by the heavy confinement of the crushed and fragmented ceramic due to the intact surrounding material and the adhesive and metallic plate, so the ceramic powder can only flow back against the advance of the projectile, along the cavity it has produced, eroding the projectile tip.

Ceramic fragmentation continues during the whole process of penetration, but the fragmentation occurring in the first microseconds after impact is the main factor in decreasing the ceramic strength. Before the end of this fragmentation stage, the tile shows its maximum resistance to penetration. After fragmentation, the projectile penetrates a conoid of comminuted, pulverized and fragmented ceramic (damaged ceramic) whose mechanical properties are lower than those of the undamaged tile and are dependent on the degree of fragmentation at each point. Crack generation as described above allows the displacement of small fragments, making projectile penetration easier. The time necessary to complete this stage is that required for the different crack fronts to pass through the ceramic tile. Den Reijer [2] assumed that the ceramic break-up time, $t_{\text {conoid, }}$, (full conoid development) depends on the time required for the radial fracture front that follows the reflected compressive wave to traverse the ceramic tile, which is

$t_{\text {conoid }} \frac{h_{\mathrm{c}}}{u_{\text {ceramic }}}+\frac{h_{\mathrm{c}}}{v_{\text {cracks }}}$

where $h_{\mathrm{c}}$ is the ceramic thickness, $u_{\text {ceramic }}$ the speed of the longitudinal elastic compressive wave, and $v_{\text {cracks }}$ the speed of radial crack front, whose maximum velocity is that of the Rayleigh waves in the material. Senf et al. [8] and Strassburger et al. [9] measured the dynamic propagation velocity of cracks in glasses and ceramics, and found values of $v_{\text {cracks }}$ in between $1 / 3$ and $1 / 6$ of $u_{\text {ceramic. Den Reijer proposed a }}$ value of $1 / 5$ of $u_{\text {ceramic }}$ to fit the numerical simulations made by Wilkins [1].

Immediately upon contact, shock waves are generated both in the ceramic tile and in the projectile, due to the compressibility of the materials. The response in both bodies would correspond essentially to uniaxial strain conditions, until the shock pressures are reduced by rarefaction waves generated by the presence of free surfaces. Ravid et al. [10] proposed an equation to determine the time $t_{1}$ needed for the complete elimination of the shock waves, which depends on the striking velocity of the projectile $v_{\mathrm{s}}$, the shock wave velocity in the projectile material $U_{\mathrm{p}}^{\mathrm{s}}$, and the diameter of the projectile $R_{\mathrm{p}}$.

$t_{1} \quad \frac{1.43 R_{\mathrm{p}}}{U_{\mathrm{p}}^{\mathrm{s}}+v_{\mathrm{s}}}$

From Hugoniot curves for tungsten carbide and alumina, and considering the geometry and velocity of the projectile involved in this problem, $t_{1}$ here has to be about $1 \mu \mathrm{s}$. According to den Reijer's equation, the time needed for the formation of the ceramic conoid for a $6.0 \mathrm{~mm}$ thick AD95 tile is about $4 \mu \mathrm{s}$, so shock wave effects appear to be unimportant in the ceramic fragmentation process.

\section{Numerical simulation}

The numerical tool used in this analysis was the finite difference computer code AUTODYN-2D [11]. For the projectile and backing-plate materials, a Steinberg-Guinan equation [12] was used, which is often adopted for solids subjected to high velocity deformation. It assumes that the shear modulus $G$ rises with pressure and falls with 
Table 3

Values of the parameters of the Steinberg Guinan model for aluminium and tungsten carbide

\begin{tabular}{lcl}
\hline Constant & Aluminium 2017-T6 & Tungsten carbide \\
\hline$G_{0}(\mathrm{~Pa})$ & $2.76 \times 10^{10}$ & $1.6 \times 10^{11}$ \\
$Y_{0}(\mathrm{~Pa})$ & $2.3 \times 10^{8}$ & $2.2 \times 10^{9}$ \\
$Y_{\max }(\mathrm{Pa})$ & $3.7 \times 10^{8}$ & $4.0 \times 10^{9}$ \\
$\beta$ & 125 & 7.7 \\
$N$ & 0.1 & 0.13 \\
$\mathrm{G}^{\prime}$ & 1.8 & 1.501 \\
$\mathrm{G}_{\mathrm{T}}^{\prime}(\mathrm{Pa} / \mathrm{K})$ & $-1.7 \times 10^{7}$ & $-2.208 \times 10^{7}$ \\
$Y_{p}^{\prime}$ & $1.8908 \times 10^{-2}$ & $2.0640 \times 10^{-2}$ \\
\hline
\end{tabular}

temperature according to the expression:

$G \quad G_{0}\left\{1+\left(\frac{G_{p}^{\prime}}{G_{0}}\right) \frac{p}{\kappa^{1 / 2}}+\left(\frac{G_{T}^{\prime}}{G_{0}}\right)(T-300)\right\}$

where $G_{p}^{\prime}$ and $G_{T}^{\prime}$ are the constants of the material $\left(G_{T}^{\prime}\right.$ being a negative constant), $T$ is the temperature in the Kelvin scale, and $\kappa$ is the compression of the materialinitial volume/actual volume. The variation of the elastic limit is taken as dependent on the pressure, the temperature and the effective plastic deformation $\epsilon^{\mathrm{P}}$

$Y \quad Y_{0}\left\{1+\left(\frac{Y_{p}^{\prime}}{Y_{0}}\right) \frac{p}{\kappa^{1 / 2}}+\left(\frac{G_{T}^{\prime}}{G_{0}}\right)(T-300)\left(1+\beta \epsilon^{\mathrm{P}}\right)^{n}\right\}$

where $Y_{p}^{\prime}, \beta$ and $n$ are the material constants. The above equation is subject to a maximum value of the elastic limit

$Y_{0}(1+\beta \epsilon)^{n} \leq Y_{\max }$

The values of the various constants for the 2017-T6 aluminium alloy and tungsten carbide are shown in Table 3.

Different material models were implemented in the computer code for the ceramic material and the adhesives, the damage model proposed by Cortés et al. [13] being adopted for the ceramic. This model associates the ceramic damage with a damage variable $\eta$, that defines the state of deterioration of the material, $\eta \quad 0$ standing for the intact material and $\eta \quad 1$ for the completely fragmented material. At a given instant, a fraction $\eta$ of the material is assumed to be pulverized and a fraction $(1-\eta)$ is still intact. The evolution of the damage is specified by the relation

$\dot{\eta} \begin{cases}\dot{\eta}_{0}\left(\sigma-\sigma_{0}\right) & \text { for } \sigma>\sigma_{0} \\ 0 & \text { for } \sigma \leq \sigma_{0}\end{cases}$

where $\sigma$ is the hydrostatic stress, $\dot{\eta}_{0}$ is a parameter of the material, and $\sigma_{0}$ the threshold of hydrostatic pressure for the

Table 4

Values of the parameters of the Cowper Symonds model for epoxy resin

\begin{tabular}{llll}
\hline$Y_{\mathrm{a} 0}(\mathrm{~Pa})$ & $C_{1}(\mathrm{~Pa})$ & $C_{2}\left(\mathrm{~s}^{-1}\right)$ & $n$ \\
\hline $4.3 \times 10^{7}$ & $1.6 \times 10^{7}$ & $2.5 \times 10^{-4}$ & 5.3 \\
\hline
\end{tabular}

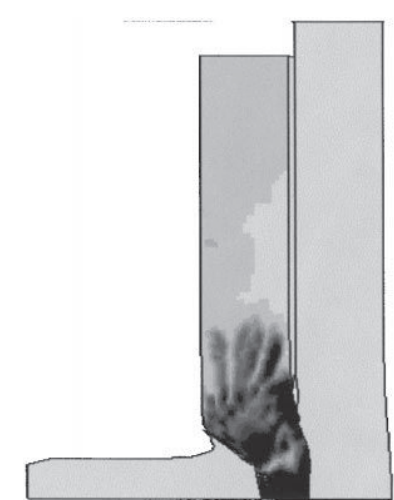

DAMAGE

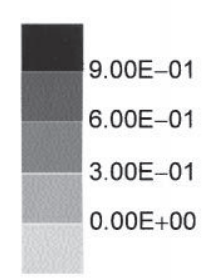

CYCLE 1472

$\mathrm{T}=8.002 \mathrm{E}-06 \mathrm{~s}$

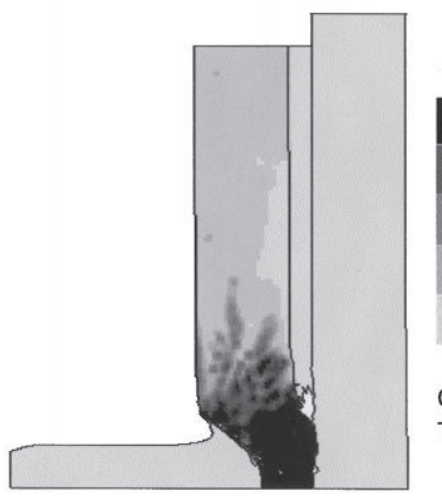

DAMAGE

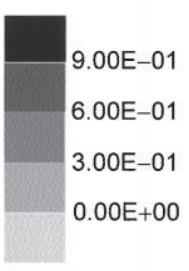

CYCLE 1520

$\mathrm{T}=8.001 \mathrm{E}-06 \mathrm{~s}$

Fig. 4. Damage contours in the ceramic tile with a $0.5 \mathrm{~mm}$ polyurethane bonding layer (top) and a $1.5 \mathrm{~mm}$ polyurethane bonding layer (bottom) $8 \mu \mathrm{s}$ after impact.

initiation of fracture. The condition of plastification is determined from the two fractions of the material as follows:

$\tau \quad(1-\eta) \tau_{\mathrm{i}}+\eta \tau_{\mathrm{c}}$

in which $\tau$ is the shear on the octahedral plane, $\tau_{\mathrm{i}}$ is the elastic limit of the intact material, and $\tau_{\mathrm{c}}$ the elastic limit of the pulverized material. Since the latter does not undergo hardening, we have

$\tau_{\mathrm{c}} \quad \mu \sigma$

where $\mu$ is the coefficient of internal friction. For the intact fraction, a Drucker-Prager criterion is adopted

$\tau_{\mathrm{i}} \quad a-b \sigma$

The parameters adopted for the simulation are those proposed by the authors of the model for the $95 \%$-purity alumina $\left(\dot{\eta}_{0} \quad 0.0025 \mathrm{~Pa}^{-1} \mathrm{~s}^{-1}, \sigma_{0} \quad 100 \mathrm{MPa}, \mu \quad 0.5\right.$, $\begin{array}{lll}a & 4.467 \times 10^{8}, b & 2.7) \text {. }\end{array}$

The behaviour of the polyurethane adhesive was considered as viscoelastic, on the basis of the variation of the elastic modulus with the strain rate (Table 1). For the epoxy resin, a Cowper-Symonds [6] equation was used, relating the elastic limit $\sigma_{\mathrm{ya}}$, the plastic deformation $\epsilon_{\mathrm{pa}}$, and the velocity of plastic deformation $\dot{\epsilon}_{\text {pa }}$

$\sigma_{\text {ya }} \quad\left(Y_{\mathrm{a} 0}+C_{1} \epsilon_{\mathrm{pa}}^{x}\right)\left(1+\left(C_{2} \dot{\epsilon}_{\mathrm{pa}}\right)^{n}\right)$ 


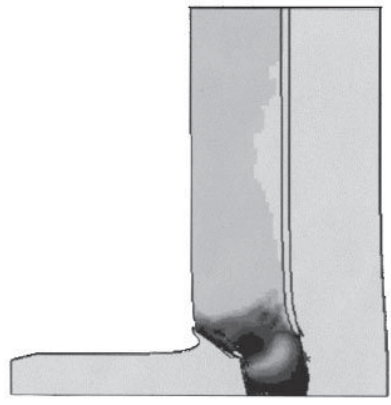

DAMAGE

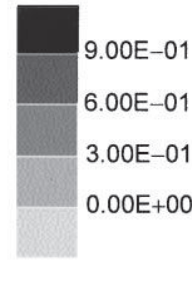

CYCLE 1470

$\mathrm{T}=8.002 \mathrm{E}-06 \mathrm{~s}$

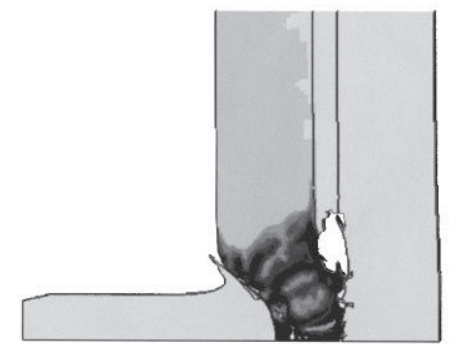

DAMAGE

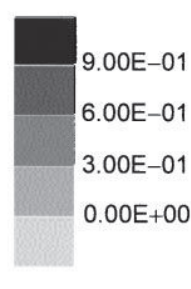

CYCLE 1590

$\mathrm{T}=8.001 \mathrm{E}-06 \mathrm{~s}$

Fig. 5. Damage contours in the ceramic tile $8 \mu \mathrm{s}$ after impact: $0.5 \mathrm{~mm}$ epoxy resin (top) and $1.5 \mathrm{~mm}$ epoxy resin (bottom).

in which $Y_{\mathrm{a} 0}, C_{1}, C_{2}, x$ and $n$ are material constants. For polymer materials, it is usual to take $x \quad 1$, and for the other constants, the values shown in Table 4 are used, adjusted to the experimental results. For the elastic modulus of the epoxy resin, its static value is adopted (2 GPa).

The results of the numerical simulations showed that one of the most influential phenomena throughout the fragmentation of the ceramic material is the appearance of tensile stresses on the rear face of the tile, and the subsequent cracking. The speed at which this occurs depends largely on the thickness of the adhesive layer. Fig. 4 shows the damage contours in the ceramic material for two thicknesses of the polyurethane adhesive. At any instant, the thicker the adhesive layer the greater the damage to the ceramic. The same effect was seen with the epoxy resin (Fig. 5). The type of adhesive also influences the fragmentation of the ceramic tile. From a comparison between Figs. 4 and 5, it appears that the ceramic damage is greater in the case of polyurethane adhesive than in that of epoxy resin. This may be due to the higher flexibility of the polyurethane.

Another phenomenon observed is that a thin adhesive layer ensures rapid contact between the ceramic tile and the aluminium plate. Subsequently the plastic deformation of the aluminium plate is more concentrated around the impact axis (Fig. 6).

\section{Full-scale fire tests}

To verify the numerical predictions with experimental results, a set of full-scale fire tests were carried out. For each type of adhesive, the thicknesses used in the numerical simulations were considered. The impact was made on the central tile of the armour, the rest of ceramic tiles placed so as to observe the extended effect of the impact (Fig. 2). The adjoining tiles are not considered in the numerical simulation; the cross-shaped arrangement of the tiles could not be represented by a two-dimensional (2D) axial-symmetry model.

From the observation of the impacted armours, some conclusions may be drawn regarding the adhesive thickness. Firstly, the area of the deformed zone of the rear face of the backing plate seems to increase with the thickness of the adhesive layer, as was observed in the numerical simulations. With the same thickness of the adhesive layer, the plastic deformed area is slightly larger with the epoxy resin than with the polyurethane adhesive.

Secondly, with the epoxy resin the damage in the impacted tile is less than that in the tile bonded with polyurethane. Also, as shown in Fig. 7, the thickness of the layer of adhesive affected the degree of fragmentation of the adjacent tiles. With a $0.5 \mathrm{~mm}$ layer of polyurethane, the

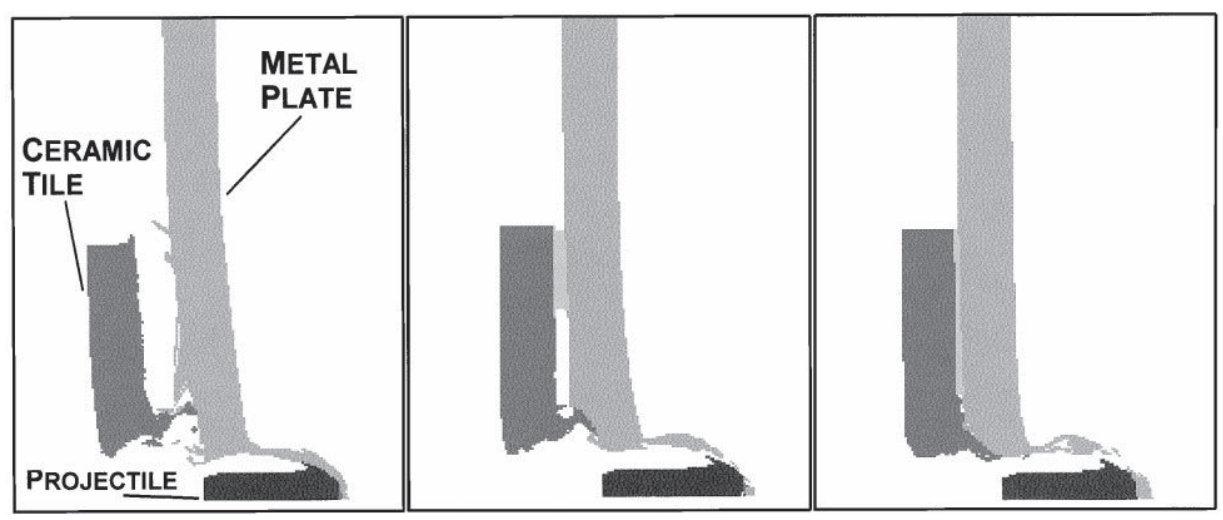

Fig. 6. Deformation of the aluminium plate $40 \mu \mathrm{s}$ after impact with three different thicknesses of polyurethane adhesive: $1.5 \mathrm{~mm}$ (left), $1.0 \mathrm{~mm}$ (centre) and $0.5 \mathrm{~mm}$ (right). 

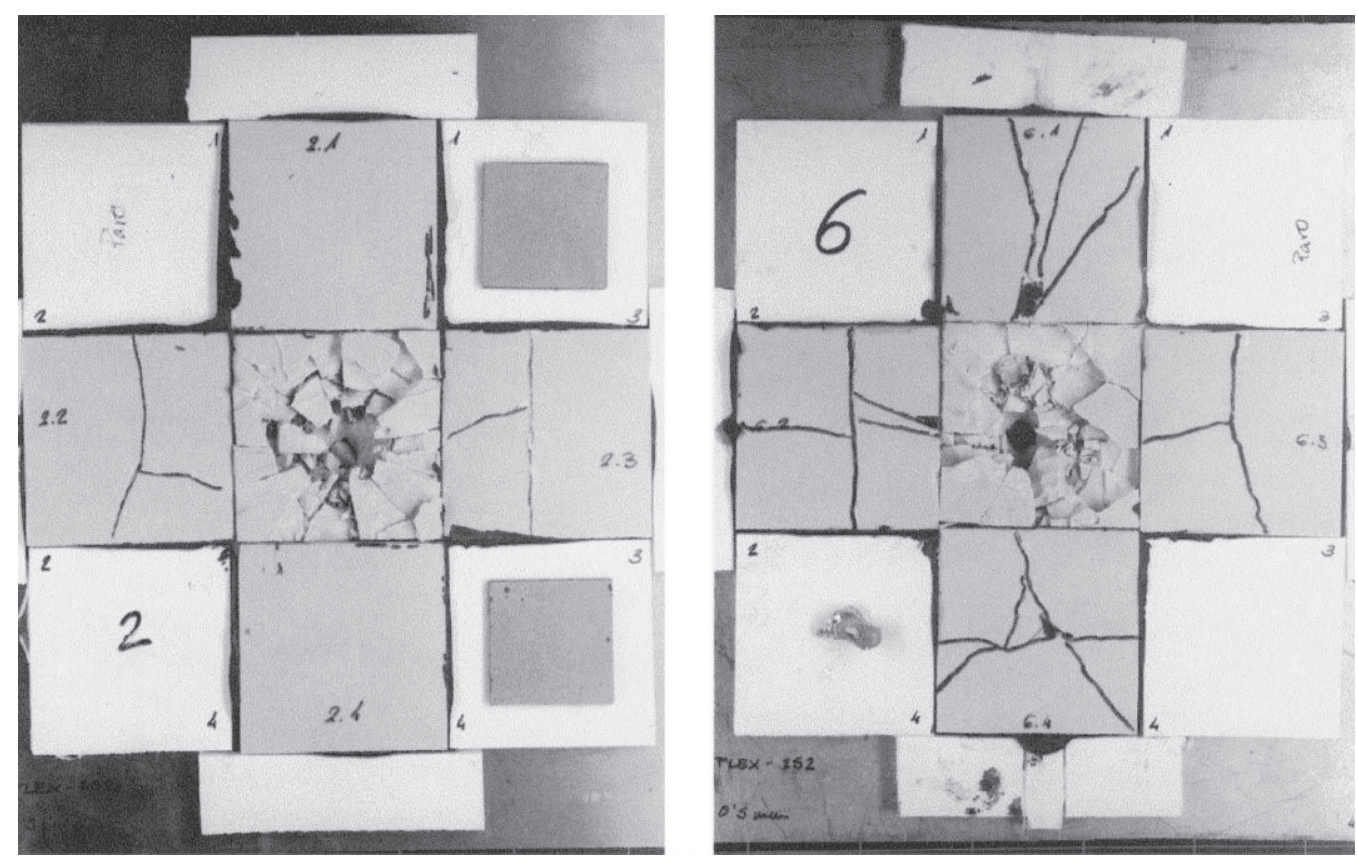

Fig. 7. Comparison of the degree of fragmentation of the adjacent tiles for a polyurethane adhesive layer of thicknesses of $1.5 \mathrm{~mm}$ (left) and $0.5 \mathrm{~mm}$ (right).

four adjacent tiles were fragmented after the impact. With a $1.5 \mathrm{~mm}$ layer of polyurethane, only two of the four adjacent tiles remained undamaged in each panel. The same effect was observed when epoxy resin was used, but with much less fragmentation of the adjacent tiles than in the case of the polyurethane bond (see Fig. 8).

The degree of fragmentation of the tiles surrounding the impacted one depends on the type and the thickness of the adhesive, and their fragmentation reduces considerably the ballistic efficiency of the armour against subsequent impacts close to the initial zone of impact. And fragmentation increases in inverse proportion to the thickness of the layer of adhesive. The thicker layer seems to damp the vibrations transmitted from the impacted zone.

\section{Engineering model}

Several engineering models have been developed [1417] for mixed armours but none of them considers the effect

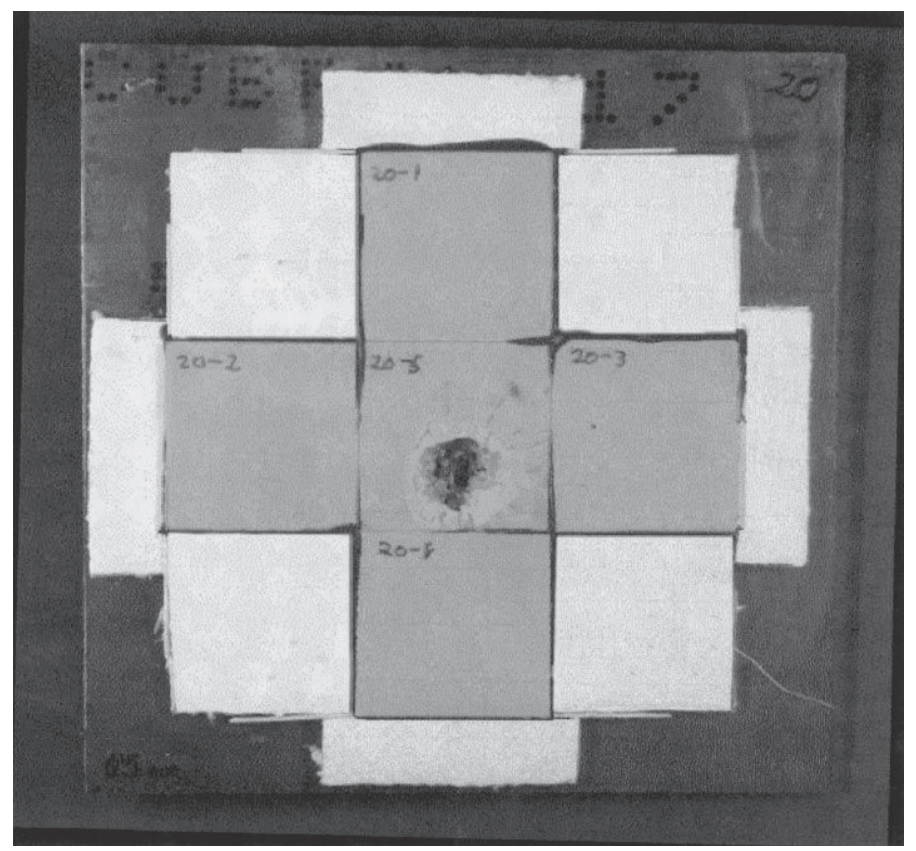

Fig. 8. Alumina/aluminium panel after impact when n $0.5 \mathrm{~mm}$ thick epoxy resin layer is used. 


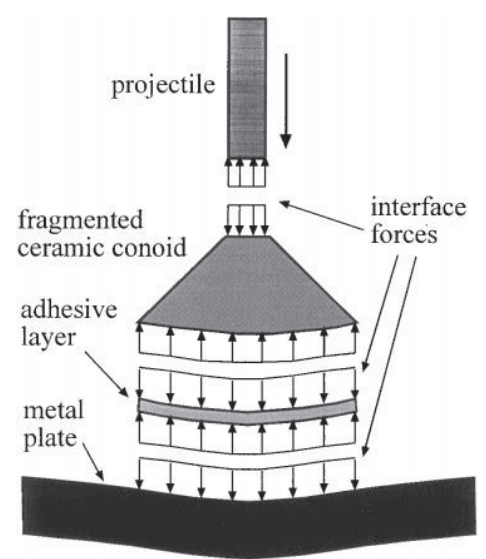

Fig. 9. Subsystems considered in the analytical model.

of the adhesive layer. The engineering model proposed here does take this layer into account. The armour was divided into interacting subsystems (Fig. 9), each with a particular dynamic behaviour.

For the projectile, the Tate-Alekseevskii model [18,19] was used, which considers the erosion of the projectile and of the impacted ceramic. The equations of the model are:

$Y_{\mathrm{p}}+\frac{1}{2} \rho_{\mathrm{p}}(v-u)^{2} \quad Y_{\mathrm{c}}+\frac{1}{2} \rho_{\mathrm{t}} u^{2}$

$\frac{\mathrm{d} L}{\mathrm{~d} t} \quad-(v-u)$

$\frac{\mathrm{d} v}{\mathrm{~d} t} \quad-\frac{Y_{\mathrm{p}}}{\rho_{\mathrm{p}} L}$

where $Y_{\mathrm{p}}$ is the dynamic strength of projectile material, $Y_{\mathrm{c}}$ is the penetration strength of the target, $\rho_{\mathrm{p}}$ and $\rho_{\mathrm{t}}$ are, respectively, the densities of the projectile and of the target, $L$ is the actual length of the projectile, $v$ is its velocity and $u$ the penetration speed. The projectile behaviour is taken as rigidperfectly plastic, so the projectile is assumed to be undeformed except for a small zone near the tip which is assumed to be plastic and will be immediately eroded. This hypothesis is reasonable because the elastic energy stored in the projectile is negligible as compared to the energy dissipated in plastic deformation and erosion.

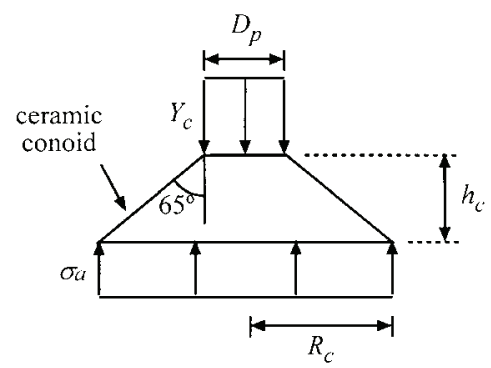

Fig. 10. Fragmented ceramic conoid, as considered in the engineering model.
For the ceramic material, the model proposed by Zaera and Sánchez-Gálvez [17] was adopted. It considers the fractured ceramic cone as a system of variable mass, since the height of the cone changes with its progressing erosion. Applying the variation equation of linear momentum in the impact direction to this system, the following expression is obtained:

$$
\begin{aligned}
Y_{\mathrm{c}} & \frac{D_{\mathrm{p}}^{2}}{4}-\sigma_{\mathrm{a}} \pi R_{\mathrm{c}}^{2} \pi \rho_{\mathrm{c}} h_{\mathrm{ct}}\left[\frac{\mathrm{d} u}{\mathrm{~d} t}\left(\frac{D_{\mathrm{p}}^{2}}{16}+\frac{R_{\mathrm{c}}^{2}}{12}+\frac{D_{\mathrm{p}} R_{\mathrm{c}}}{12}\right)\right. \\
+ & \left.\frac{\mathrm{d} u_{\mathrm{c}}}{\mathrm{d} t}\left(\frac{D_{\mathrm{p}}^{2}}{48}+\frac{R_{\mathrm{c}}^{2}}{4}+\frac{D_{\mathrm{p}} R_{\mathrm{c}}}{12}\right)\right] \\
& +\pi \rho_{\mathrm{c}} \frac{\mathrm{d} h_{\mathrm{ct}}}{\mathrm{d} t}\left[u\left(\frac{7 D_{\mathrm{p}}^{2}}{48}+\frac{5 R_{\mathrm{c}}^{2}}{12}\right)-u_{\mathrm{c}}\left(\frac{D_{\mathrm{p}}^{2}}{16}+\frac{13 R_{\mathrm{c}}^{2}}{12}+\frac{D_{\mathrm{p}} R_{\mathrm{c}}}{12}\right)\right] \\
& +\pi \rho_{\mathrm{c}} h_{\mathrm{ct}} \frac{\mathrm{d} R_{\mathrm{c}}}{\mathrm{d} t}\left[u\left(\frac{D_{\mathrm{p}}}{12}+\frac{R_{\mathrm{c}}}{6}\right)+u_{\mathrm{c}}\left(\frac{D_{\mathrm{p}}}{6}+\frac{R_{\mathrm{c}}}{2}\right)\right]
\end{aligned}
$$

$D_{\mathrm{p}}$ being the diameter of the projectile, $R_{\mathrm{c}}$ the radius of the base of the ceramic cone, $\sigma_{\mathrm{a}}$ the pressure between the base of the conoid and the adhesive layer, $\rho_{\mathrm{c}}$ the density of the ceramic, $h_{\mathrm{ct}}$ the height of the ceramic conoid, and $u_{\mathrm{c}}$ the velocity of the ceramic-adhesive interface (Fig. 10). The radius of the base of the ceramic conoid $R_{\mathrm{c}}$ is obtained by taking an angle of $65^{\circ}$ between the cracks limiting the conoid and the impact axis, which coincides with that of Hertzian cracks [2,15].

For the metal plate, the equation was one of energy balance:

$\dot{W} \quad \dot{E}_{\mathrm{k}}+\dot{E}_{\mathrm{p}}$

in which $W$ is the work of forces outside the plate, $E_{\mathrm{k}}$ is its kinetic energy, and $E_{\mathrm{p}}$ the energy dissipated by plastic deformation. Taking a displacement field for the metal plate dependent on the displacement of the axis of the plate $u_{\mathrm{b}}$, the three terms of the equation are functions of $u_{\mathrm{b}}$ and its derivatives $\dot{u}_{\mathrm{b}}$ and $\ddot{u}_{\mathrm{b}}$. Then, assuming that the displacement $u(r)$ of the plate may be described through two paraboloids (Fig. 11); the equation is:

$u(r) \begin{cases}-\frac{2 u_{\mathrm{b}}}{R_{\mathrm{b}}^{2}} r^{2}+u_{\mathrm{b}} & r \leq R_{\mathrm{b}} \\ \frac{2 u_{\mathrm{b}}}{R_{\mathrm{b}}^{2}} r^{2}-\frac{4 u_{\mathrm{b}}}{R_{\mathrm{b}}} r+2 u_{\mathrm{b}} & r>R_{\mathrm{b}}\end{cases}$

where $R_{\mathrm{b}}$ is the radius of the plastically deformed zone. This can be estimated as $3 / 2$ of the initial radius of the base of the conoid of fragmented ceramic material [2].

The kinetic energy of the plate may be expressed as

$E_{\mathrm{k}} \quad \int_{0}^{R_{\mathrm{b}}} \frac{1}{2} v(r)^{2} \rho_{\mathrm{b}} h_{\mathrm{b}} 2 \pi r \mathrm{~d} r \quad \frac{7}{80} \pi \rho_{\mathrm{b}} h_{\mathrm{b}} R_{\mathrm{b}}^{2} \dot{u}_{\mathrm{b}}^{2}$

in which $\rho_{\mathrm{b}}$ is the density of the metallic plate and $h_{\mathrm{b}}$ its 


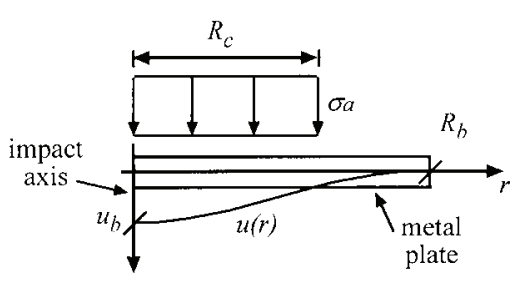

Fig. 11. Deformation of the metallic backing plate, as considered in the engineering model.

thickness. The plastic work dissipated in increasing the length of the central fibre of the plate is obtained from the expression

$$
\begin{aligned}
E_{\mathrm{pN}} \quad \int_{0}^{R_{\mathrm{b}}} N_{\text {plas }} \epsilon 2 \pi r \mathrm{~d} r \\
=\frac{N_{\text {plas }} \pi R_{\mathrm{b}}^{2}\left(-4 u_{\mathrm{p}}+2 u_{\mathrm{p}} \sqrt{1+\frac{4 u_{\mathrm{b}}^{2}}{R_{\mathrm{b}}^{2}}}\right)+R_{\mathrm{b}} \operatorname{arcsinh}\left(\frac{2 u_{\mathrm{b}}}{R_{\mathrm{b}}}\right)}{4 u_{\mathrm{b}}}
\end{aligned}
$$

where $N_{\text {plas }}$ is the fully plastic in-plane force and $\epsilon$ is the inplane strain. The energy dissipated in radial curvature may be obtained from

$$
E_{\mathrm{pR}} \quad \int_{0}^{R_{\mathrm{b}}} M_{\text {plas }} \kappa_{\mathrm{r}} 2 \pi r \mathrm{~d} r \quad 2 M_{\mathrm{plas}} \pi R_{\mathrm{b}} \operatorname{arctg}\left(\frac{2 u_{\mathrm{b}}}{R_{\mathrm{b}}}\right)
$$

in which $M_{\text {plas }}$ is the fully plastic bending moment and $\kappa_{\mathrm{r}}$ is the radial curvature. According to Woodward et al. [20] and Johnson et al. [21], the plastic work done in circumferential curvature is close to that of a radial curvature, so

$$
E_{\mathrm{p}} \quad E_{\mathrm{pN}}+2 E_{\mathrm{pR}}
$$

The work rate done by external forces may be calculated from

$$
\begin{aligned}
& \frac{\mathrm{d} W_{\mathrm{ext}}}{\mathrm{d} t} \quad \int_{0}^{R_{\mathrm{c}}} 2 \pi r \sigma_{\mathrm{a}} \frac{\mathrm{d} u}{\mathrm{~d} t} \mathrm{~d} r \\
& \begin{cases}\dot{u}_{\mathrm{b}} \pi \sigma_{\mathrm{a}} R_{\mathrm{c}}^{2}\left(1-\left(\frac{R_{\mathrm{c}}}{R_{\mathrm{b}}}\right)^{2}\right) & R_{\mathrm{c}}<\frac{R_{\mathrm{b}}}{2} \\
\frac{\dot{u}_{\mathrm{b}} \pi \sigma_{\mathrm{a}}}{24 R_{\mathrm{b}}^{2}}\left(-R_{\mathrm{b}}^{4}+48 R_{\mathrm{b}}^{2} R_{\mathrm{c}}^{2}-64 R_{\mathrm{b}} R_{\mathrm{c}}^{3}+24 R_{\mathrm{c}}^{4}\right) & R_{\mathrm{c}} \geq \frac{R_{\mathrm{b}}}{2}\end{cases}
\end{aligned}
$$

Given the low mass of the affected adhesive layer, no inertial effect of this material was incorporated into the model, so this layer transmits the whole force exerted by the ceramic cone to the backing plate. The strain $\epsilon_{\mathrm{a}}$, and strain rate $\dot{\epsilon}_{\mathrm{a}}$ at the adhesive layer is calculated with the equations:

$$
\begin{array}{cc}
\epsilon_{\mathrm{a}} & \frac{u_{\mathrm{c}}-u_{\mathrm{b}}}{h_{\mathrm{a}}} \\
\dot{\epsilon}_{\mathrm{a}} & \frac{\dot{u}_{\mathrm{c}}-\dot{u}_{\mathrm{b}}}{h_{\mathrm{a}}}
\end{array}
$$

in which $h_{\mathrm{a}}$ is the initial thickness of the adhesive layer. The constitutive models used in the numerical simulation were adopted for the adhesives.

With this set of equations it is possible to calculate the armour response. The validation of the analytical model was made by comparing its predicted results with those of the full numerical simulations. In Fig. 12, the displacements of the projectile tail, projectile tip and metal backing plate are plotted for the numerical and analytical solutions of an impact problem. The loss of kinetic energy of the projectile after perforation was $30 \%$ in the results given by the numerical tool, and $32 \%$ in those by the analytical one.

\section{Discussion of results}

Two aspects were studied to evaluate the effect of the thickness and type of adhesive on the impact behaviour of

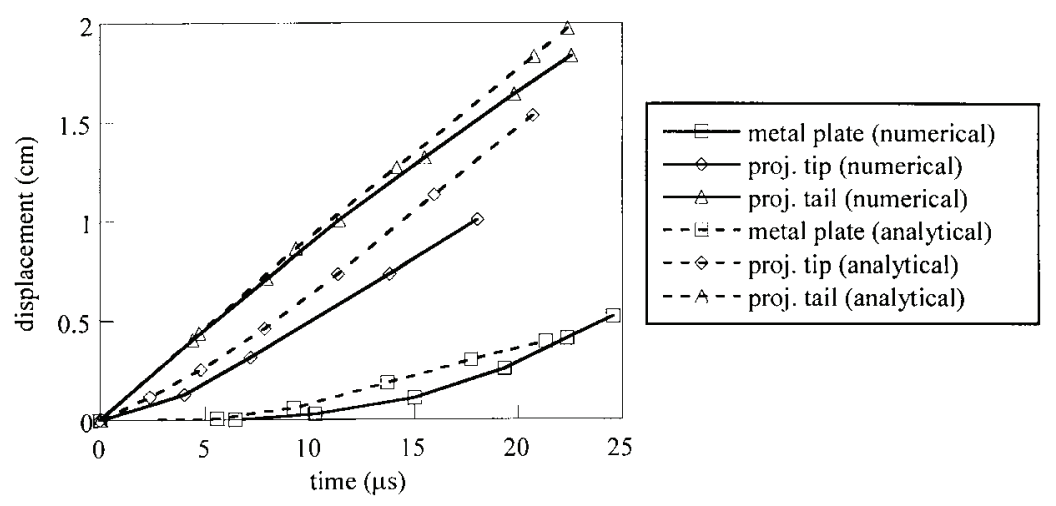

Fig. 12. Impact of a 7.62 armour piercing projectile on a $6.0 \mathrm{~mm}$ thick alumina tile bonded with a $1.5 \mathrm{~mm}$ thick polyurethane to a $6.0 \mathrm{~mm}$ thick aluminium plate. 
Table 5

Mechanical properties of alumina and adhesives

\begin{tabular}{|c|c|c|c|c|}
\hline & Density $\left(\mathrm{kg} / \mathrm{m}^{3}\right)$ & $\begin{array}{l}\text { Elastic modulus } \\
\text { (static values) }(\mathrm{MPa})\end{array}$ & $\begin{array}{l}\text { Longitudinal elastic } \\
\text { wave speed }(\mathrm{m} / \mathrm{s})\end{array}$ & $\begin{array}{l}\text { Mechanical } \\
\text { impedance }\left(\mathrm{kg} / \mathrm{s} / \mathrm{m}^{2}\right)\end{array}$ \\
\hline Alumina $95 \%$ & 3740 & 310000 & 9100 & $34.0 \times 10^{6}$ \\
\hline Polyurethane & 1150 & 10 & 100 & $0.1 \times 10^{6}$ \\
\hline Epoxy resin & 1200 & 2000 & 1300 & $1.6 \times 10^{6}$ \\
\hline
\end{tabular}

the armour: (i) damage in the ceramic tiles and, (ii) deformation of the metallic plate.

\subsection{Damage in the ceramic tiles}

The speed of fragmentation of the ceramic tile is determinant in its resistance to penetration and its ability to erode the projectile. One of the most important phenomena during this fragmentation is the appearance of tensile stresses in the rear face of the tile, and thus the subsequent cracking of the ceramic material $[2,3]$. The speed at which these stresses arise, and their intensity, depend basically on the speed at which the compressive waves reach the rear face of the ceramic tile as well as on the amplitude of the traction waves reflected onto the ceramic-adhesive interface. These variables were analysed only in terms of elastic waves, since in the absence of shock waves (which according to the expression of Ravid et al. used earlier, disappear almost immediately), the tension waves reaching the ceramic-adhesive interface are elastic.

To estimate the ratio between the refracted and incident energy of the elastic waves at this interface, the 1D theory of elastic wave propagation may be used:

$$
\frac{E_{\text {refracted }}}{E_{\text {incident }}} \quad 1-\left(\frac{2}{1+I}-1\right)^{2}
$$

where $I$ is the mechanical impedance ratio given by

$I \quad \frac{I_{\text {ceramic }}}{I_{\text {adhesive }}} \quad \frac{\sqrt{E_{\text {ceramic }} \rho_{\text {ceramic }}}}{\sqrt{E_{\text {adhesive }} \rho_{\text {adhesive }}}}$

The mechanical impedances of AD95, polyurethane and epoxy resin are shown in Table 5.

About $16 \%$ of the incident energy is transmitted to the layer of epoxy resin but only $1.2 \%$ to that of polyurethane (Fig. 13), which means that in this case nearly all the inci-

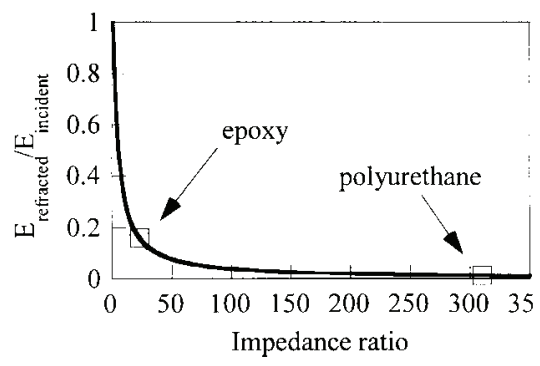

Fig. 13. Refracted energy to the adhesive layer for alumina/polyurethane and alumina/epoxy systems. dent energy is reflected back to the ceramic. This increases the tensile stresses in the tile and its subsequent cracking as was seen in the numerical simulations. As reported by den Reijer [2], the energy dissipated in the cracking of the tile is only about $5 \%$ of the kinetic energy of the projectile; the remaining impact energy is dissipated in the plastic deformation of the metal backing plate and in that of the projectile during its erosion. A premature fragmentation of the ceramic tile reduces its erosive capacity and consequently the ballistic efficiency of the armour.

For better ballistic performance of the ceramic tile, the layer of adhesive should transmit the impulsive load to the metallic backing plate as rapidly as possible, since the metal has a higher mechanical impedance than the adhesive material and would absorb much more energy at earlier stages of the ceramic fragmentation. The compressive wave transmitted by the ceramic tile to the layer of adhesive travels through the adhesive to the adhesive-aluminium interface where it is partly transmitted to the backing plate and partly reflected back as a compressive wave, due to the higher mechanical impedance of the aluminium. Once the reflected wave, travelling in the adhesive layer in the opposite direction to the projectile advance, reaches the ceramic-adhesive interface again, the effect of the metallic backing plate comes into play in the ballistic performance of the ceramic, preventing the bending of the tile. The time necessary for the compressive waves to cross the adhesive layer and return is shown in Table 6 for the different layer thicknesses. Obviously, the thicker the adhesive the longer the time. With the thicker layer, the ceramic tile remains much longer unsupported by the aluminium plate, and fragmentation is more rapid, mainly due to bending. This is seen also in the numerical simulation, where greater and earlier damage develops in the ceramic tile with the increase of the thickness of the adhesive layer. Data reported in Table 6 may also explain why the fragmentation process is slower with epoxy resin. As mentioned earlier, the time needed for the development of the ceramic conoid in the analysed problem was about $4 \mu \mathrm{s}$. Since the times for epoxy resins are below $4 \mu \mathrm{s}$, the supporting effect of the aluminium backing plate is much more effective than with polyurethane adhesive.

\subsection{Plastification of the metallic plate}

Both the numerical study and the experimental results show that the thicker the layer of adhesive, the larger the 
Table 6

Time required for compressive waves to travel through the adhesive layer and return

\begin{tabular}{lll}
\hline Layer thickness $(\mathrm{mm})$ & Epoxy resin $(\mu \mathrm{s})$ & Polyurethane $(\mu \mathrm{s})$ \\
\hline 0.5 & 0.77 & 10 \\
1.0 & 1.54 & 20 \\
1.5 & 2.31 & 30 \\
\hline
\end{tabular}

area affected by plastic deformation of the metallic plate. This leads to a greater absorption of the kinetic energy of the projectile by the backing plate. In addition, the ceramic tile is fragmented earlier when the adhesive layer is thicker. The two effects of the ceramic/metal panel that are conditioned by the thickness of the layer of adhesive favour the efficacy of the armour in opposite ways: a thin layer of adhesive hinders the premature fragmentation of the tile, but the deformation of the metallic plate is more concentrated, so it dissipates less energy in plastic deformation. Several reports $[1,2]$ indicate that the ceramic is the most important component of the armour in causing the erosion of the projectile; so it may be assumed that the armour is more effective with a thin layer of adhesive. To check this last assertion, new full numerical analyses were made, maintaining the backing plate thickness at $6 \mathrm{~mm}$ and varying those of the ceramic and adhesive layers. Fig. 14 shows the loss of kinetic energy of the projectile against the adhesive
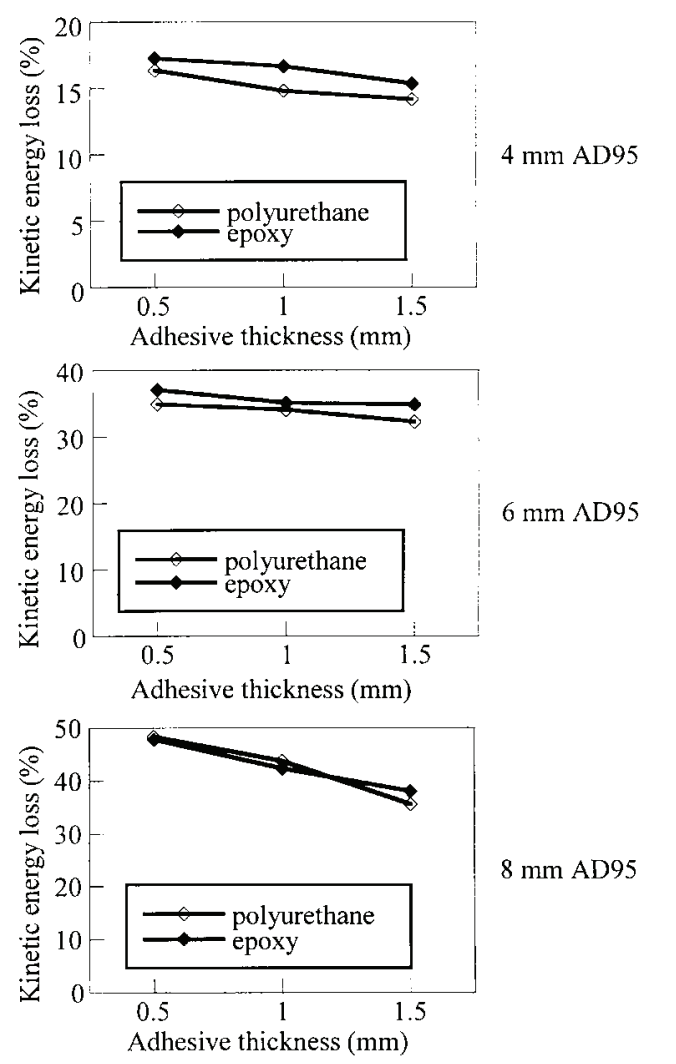

Fig. 14. Projectile kinetic energy loss versus both adhesive type and thickness. thickness. In all cases, the thinner layer improves the ballistic efficiency of the protective armour since damage to the ceramic is delayed and the projectile suffers more erosion. This improvement is more evident in thicker tiles; the greater erosive effect of a thicker ceramic tile is considerably diminished if the layer of adhesive is too thick.

\section{Conclusions}

In view of the scant information available about the effect of the layer of adhesive on the ballistic efficiency of ceramic/metal armour plating, this study tries to analyse its influence, which admitted by other authors. The study focuses on the two variables that most affect the performance of the armour: the degree of fragmentation of the ceramic material, and the transmission of the impulsive energy to the backing plate. The first of these has a negative effect on the erosive capacity of the ceramic, and the second has the positive effect of helping to dissipate the energy in plastic deformation of the metal.

A numerical simulation had to be used since the information provided by practical high speed impact tests is difficult to quantify. The impossibility of a precise control of the loading, unlike that of quasi-static tests, and the difficulties of measuring positions, speeds or stresses, mean that recourse is made to mathematical models to follow in detail the physical processes involved in impact. Also, fire tests were made to check some of the conclusions drawn from the numerical simulation.

The study showed that the thicker layer of adhesive leads to a wider area of plastic deformation of the metallic backing plate, which helps to absorb the kinetic energy of the projectile. On the other hand, the ceramic tile is shattered earlier when the adhesive layer is thicker. These have contrary effects on the resistance capacity of the armour plating but the fragmentation of the ceramic material is expected to be of greater significance. The thickness of the layer of adhesive should be reduced as far as possible, particularly with thicker tiles, so as to delay their fragmentation and augment the erosion of the projectile. However, the experimental results showed that a thicker layer of adhesive cushions the impact on the adjacent tiles and reduces the risk of their fragmentation.

An engineering model was developed, not so precise as the numerical code, but convenient for rapid calculations, especially at the preliminary stages of armour design. The simple constitutive models used for the materials can be adjusted with parameters such as the modulus of elasticity or the elastic limit which are easily determined. The model was confirmed by the results of the numerical simulation.

\section{Acknowledgements}

The authors are indebted to the Dirección General de 
Enseñanza Superior (DGES) for the financial support of this work (Project PB-0380).

\section{References}

[1] Wilkins ML. Mechanics of penetration and perforation. Int J Engng Sci 1978;16:793 807.

[2] den Reijer PC. Impact on ceramic faced armours. PhD thesis, Delft University of Technology, 1991.

[3] Mayseless M, Goldsmith W, Virostek SP, Finnegan SA. Impact on ceramic targets. J Appl Mech 1987;54:373 8.

[4] Savage G. Ceramic armour. Defence Aerosp 1990;August:487 92.

[5] Marshall J. Composite ballistic armour. Proceedings of the 1st International Conference on Composites Engineering, ICCE/1, 1994. p. 10578.

[6] Grouch IG, Greaves LJ, Ruiz C, Harding J. Dynamic compression of toughened epoxy interlayers in adhesively bonded aluminium laminates. J Phys IV 1994;4:201 6.

[7] Shockey DA, Marchand AH, Skaggs SR, Cort GE, Burkett MW, Parker R. Failure phenomenology of confined ceramic targets and impacting rods. Int J Impact Engng 1990;9:263 75.

[8] Senf H, Strassburger E, Rothenhäusler H. Stress wave induced damage and fracture in impacted glasses. J Phys IV 1994;3:741 6.

[9] Strassburger E, Senf H, Rothenhäusler H. Fracture propagation during impact in three types of ceramics. J Phys IV 1994;3:653 8.

[10] Ravid M, Bodner SR, Holcman I. Analysis of very high speed impact. Int J Engng Sci 1986;25:473 82.
[11] AUTODYN-2D. Century Dynamics Ltd., Dynamic House, Hurst Road, Horsam, West Sussex, England, 1998.

[12] Steinberg DJ, Cochran SG, Guinan MW. Constitutive model for metals applicable at high strain rates. J Appl Phys 1980;51(3): 1498504.

[13] Cortés R, Navarro C, Martínez MA, Rodriguez J, Sánchez-Gálvez V. Numerical modelling of normal impact on ceramic composite armours. Int J Impact Engng 1992;12:639 51.

[14] Florence AL. Interaction of projectiles and composite armour Part II. Stanford Research Institute, AMRA CR 67-05 (F) Report, 1969.

[15] Woodward RL. A simple one-dimensional approach to modelling ceramic armour defeat. Int J Impact Engng 1990;9:455 74.

[16] Walker JD, Anderson CE, Jr. An analytical model for ceramic-faced light armors, Proceedings of the 16th International Symposium on Ballistics, 1996. p. 28998.

[17] Zaera R, Sánchez-Gálvez V. Analytical modelling of normal and oblique ballistic impact on ceramic/metal lightweight armours. Int J Impact Engng 1998;21:133 48.

[18] Tate A. A theory for the deceleration of long rods after impact. J Mech Phys Solids 1967;15:387 99.

[19] Alekseevskii VP. Penetration of a rod into a target at high velocity, Combustion, explosion and shock waves, vol. 2. New York: Faraday Press, 1996.

[20] Woodward RL, O'Donnell RG, Baxter BJ, Nicol B, Pattie SD. Energy absorption in the failure of ceramic composite armours. Mater Forum 1989;13:174 81 .

[21] Johnson W. Impact strength of materials. London: Edward Arnold, 1972. 